
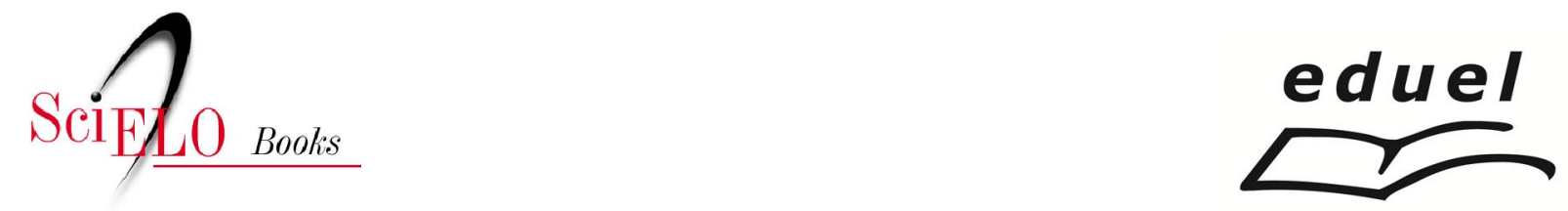

\title{
Epidemiologia e impacto da toxoplasmose congênita
}

\author{
Regina Mitsuka-Breganó \\ Fabiana Maria Ruiz Lopes-Mori \\ Italmar Teodorico Navarro \\ (orgs.)
}

\section{SciELO Books / SciELO Livros / SciELO Libros}

MITSUKA-BREGANÓ, R., LOPES-MORI, FMR., and NAVARRO, IT., orgs. Toxoplasmose adquirida na gestação e congênita: vigilância em saúde, diagnóstico, tratamento e condutas [online]. Londrina: EDUEL, 2010. Epidemiologia e impacto da toxoplasmose congênita. pp. 5-9. ISBN 978-

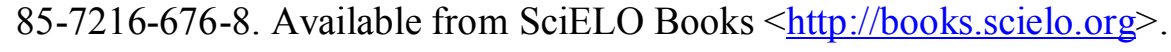

\section{(1) $(0)$}

All the contents of this work, except where otherwise noted, is licensed under a Creative Commons Attribution-Non Commercial-ShareAlike 3.0 Unported.

Todo o conteúdo deste trabalho, exceto quando houver ressalva, é publicado sob a licença Creative Commons Atribuição Uso Não Comercial - Partilha nos Mesmos Termos 3.0 Não adaptada.

Todo el contenido de esta obra, excepto donde se indique lo contrario, está bajo licencia de la licencia Creative Commons Reconocimento-NoComercial-CompartirIgual 3.0 Unported. 


\section{Epidemiologia e impacto da toxoplasmose congênita}

A prevalência de anticorpos IgG específicos anti-T. gondii apresenta variações regionais devido a diferenças climáticas e, sobretudo, culturais da população. Inquéritos sorológicos realizados em diversas regiões do Brasil estão apresentados no quadro 1 e a prevalência em gestantes em outros países estão resumidas no quadro 2. 


\begin{tabular}{|c|c|c|c|c|}
\hline Local & $\begin{array}{l}\text { Período de } \\
\text { realização }\end{array}$ & $\begin{array}{l}\text { Número de ges- } \\
\text { tantes avaliadas }\end{array}$ & $\begin{array}{l}\text { Soropositi- } \\
\text { vidade (\%) }\end{array}$ & Referência \\
\hline Natal (RN) & 2007 & 190 & 66,3 & $\begin{array}{l}\text { Barbosa; Holanda; } \\
\text { Andrade-Neto, (2009) }\end{array}$ \\
\hline Recife (PE) & 2004-2005 & 503 & 74,7 & Porto et al., (2008) \\
\hline Bahia & 1998-2000 & 2632 & 64,9 & $\begin{array}{l}\text { Nascimento et al., } \\
(2002)\end{array}$ \\
\hline $\begin{array}{l}\text { Mato Grosso do } \\
\text { Sul }\end{array}$ & 2002-2003 & 32512 & 91,6 & $\begin{array}{l}\text { Figueiró-Filho et al., } \\
\text { (2005) }\end{array}$ \\
\hline $\begin{array}{l}\text { Noroeste do } \\
\text { estado de São } \\
\text { Paulo }\end{array}$ & 2005-2006 & 232 & 57,3 & Galisteu et al., (2007) \\
\hline Araraquara (SP) & 2005 & 200 & 58,0 & $\begin{array}{l}\text { Isabel; Costa; Simões, } \\
(2007)\end{array}$ \\
\hline Londrina (PR) & 1996-1998 & 1559 & 67,0 & Reiche et al., (2000) \\
\hline Londrina (PR) & 2006 & 492 & 49,2 & Lopes et al., (2009) \\
\hline $\begin{array}{l}\text { Caxias do Sul } \\
\text { (RS) }\end{array}$ & 2004 & 458 & 31,0 & $\begin{array}{l}\text { Detanico; Basso, } \\
(2006)\end{array}$ \\
\hline $\begin{array}{l}\text { Noroeste do } \\
\text { estado do Rio } \\
\text { Grande do Sul }\end{array}$ & 1997-1998 & 2126 & 74,5 & Spalding et al., (2005) \\
\hline $\begin{array}{l}\text { Passo Fundo } \\
\text { (RS) }\end{array}$ & 2001-2002 & 1250 & 48,5 & $\begin{array}{l}\text { Mozzatto; Procianoy, } \\
(2003)\end{array}$ \\
\hline $\begin{array}{l}\text { Porto Alegre } \\
\text { (RS) }\end{array}$ & 2000 & 1261 & 59,8 & Varella et al., (2003) \\
\hline $\begin{array}{l}\text { Porto Alegre } \\
\text { (RS) }\end{array}$ & $2002-2003$ & 2477 & 67,3 & Lago et al., (2009) \\
\hline
\end{tabular}

Quadro 1 - Ocorrência de anticorpos IgG anti-Toxoplasma gondii em gestantes de diversas localidades do Brasil. 


\begin{tabular}{|c|c|c|c|c|}
\hline Local & $\begin{array}{l}\text { Período de } \\
\text { realização }\end{array}$ & $\begin{array}{l}\text { Número de ges- } \\
\text { tantes avaliadas }\end{array}$ & $\begin{array}{l}\text { Soropositivi- } \\
\text { dade }(\%)\end{array}$ & Referência \\
\hline França & 1995 & 13459 & 54,3 & Ancelle et al. (1996) \\
\hline Eslovênia & 1996-1999 & 21270 & 34,0 & $\begin{array}{l}\text { Logar; Novak-Anto- } \\
\text { lic; Zore. (1995) }\end{array}$ \\
\hline $\begin{array}{l}\text { Illa de Creta, } \\
\text { Grécia }\end{array}$ & $1998-2003$ & 5532 & 29,4 & $\begin{array}{l}\text { Antoniou et al. } \\
\text { (2004) }\end{array}$ \\
\hline Estados Unidos & $1999-2000$ & 2221 & 14,9 & Jones et al. (2001) \\
\hline Polônia & $1998-2000$ & 2656 & 43,7 & $\begin{array}{l}\text { Paul; Petersen; } \\
\text { Szczapa (2001) }\end{array}$ \\
\hline $\begin{array}{l}\text { Kent, Reino } \\
\text { Unido }\end{array}$ & 1999-2001 & 1923 & 9,1 & Nash et al. (2005) \\
\hline Austria & 2002 & - & 36,0 & Aspock (2003) \\
\hline $\begin{array}{l}\text { República } \\
\text { Democrática } \\
\text { de São Tomé e } \\
\text { Príncipe, Guiné }\end{array}$ & $2003-2004$ & 499 & 75,2 & Hung et al. (2007) \\
\hline $\begin{array}{l}\text { Changchun, } \\
\text { China }\end{array}$ & 2006 & 235 & 10,3 & Liu et al. (2009) \\
\hline
\end{tabular}

Quadro 2 - Ocorrência de anticorpos lgG anti-Toxoplasma gondii em gestantes de diferentes locais do mundo.

No quadro 3 estão apresentados alguns trabalhos sobre a incidência da toxoplasmose congênita em diversas regiões do Brasil, demonstrando, também, grande variação regional. Porém, estes dados não podem ser diretamente comparados devido à variação metodológica da pesquisa empregada em cada trabalho revisado. 


\begin{tabular}{|l|l|l|l|l|}
\hline & $\begin{array}{l}\text { Incidência/ } \\
1.000 \text { nasci- } \\
\text { mentos }\end{array}$ & $\begin{array}{l}\text { Número de } \\
\text { amostras }\end{array}$ & Metodologia & Referência \\
\hline $\begin{array}{l}\text { Diversas } \\
\text { regiōes do } \\
\text { Brasil }\end{array}$ & 0,3 & 140.914 & $\begin{array}{l}\text { Pesquisa de anticorpos } \\
\text { lgM, em papel de filtro }\end{array}$ & $\begin{array}{l}\text { Neto et al. } \\
\text { (2000) }\end{array}$ \\
\hline $\begin{array}{l}\text { Uberlândia } \\
\text { (MG) }\end{array}$ & 5,0 & 805 & $\begin{array}{l}\text { Pesquisa de lgM e/ } \\
\text { ou lgA do sangue de }\end{array}$ & $\begin{array}{l}\text { Segundo et al. } \\
\text { cordão umbilical }\end{array}$ \\
\hline $\begin{array}{l}\text { Passo Fundo } \\
\text { (RS) }\end{array}$ & 0,8 & 1.250 & $\begin{array}{l}\text { Pesquisa de anticor- } \\
\text { pos IgM de amostras } \\
\text { de sangue do cordão } \\
\text { umbilical }\end{array}$ & $\begin{array}{l}\text { Mozzatto e } \\
\text { Procianoy } \\
\text { (2003) }\end{array}$ \\
\hline $\begin{array}{l}\text { Porto Ale- } \\
\text { gre (RS) }\end{array}$ & 1,2 & 2.513 & $\begin{array}{l}\text { Acompanhamento da } \\
\text { gestante e da criança }\end{array}$ & $\begin{array}{l}\text { Lago et al. } \\
\text { (2009) }\end{array}$ \\
\hline $\begin{array}{l}\text { Noroeste do } \\
\text { Rio Grande } \\
\text { do Sul }\end{array}$ & 2,2 & 2.126 & $\begin{array}{l}\text { Acompanhamento da } \\
\text { gestante e da criança }\end{array}$ & $\begin{array}{l}\text { Spalding et al. } \\
\text { (2003) }\end{array}$ \\
\hline
\end{tabular}

Quadro 3 - Incidência da toxoplasmose congênita no Brasil

Avelino et al. (2003), em um estudo de Coorte realizado com mulheres em idade fértil inicialmente soronegativas para a toxoplasmose, encontraram uma taxa de soroconversão de 8,6\% em Goiânia (GO). Os autores compararam 522 mulheres grávidas com 592 não grávidas, concluindo que as gestantes apresentaram 2,2 vezes mais chance de adquirir a infecção e, se fosse adolescente, o risco aumentava para 7,7 vezes, demonstrando que a gestação pode ser um fator de risco para a infecção. A soroconversão ocorreu mais no segundo trimestre da gravidez e a taxa estimada de infecção fetal foi calculada em 34,5:1.000 nascimentos. Essa pesquisa revelou a taxa de soroconversão materna mais elevada registrada na literatura e apontou para a necessidade de prevenção primária e secundária em todas as gestantes de risco. 
Outro estudo realizado em Brasília, no Distrito Federal, demonstrou uma taxa de soroconversão materna de $0,6 \%$ em 2.636 gestantes avaliadas. (NÓBREGA; KARNIKOWSKI, 2005).

Lopes et al. (2009) avaliaram vários fatores que poderiam estar envolvidos na infecção por T. gondii em gestantes atendidas nas Unidades Básicas de Saúde de Londrina. Os resultados revelaram uma soroprevalência de anticorpos IgG anti-T. gondii de 49,2\% e lgM anti- $T$. gondii de 1,2\% em 492 gestantes avaliadas. Os fatores como idade, renda per capita, grau de escolaridade, presença de gato na residência e hábito de ingerir verduras e legumes crus foram associados à maior chance de adquirir a toxoplasmose, enquanto que a ingestão de carnes cruas ou mal passadas e o contato com solo não demonstraram esta associação.

Atoxoplasmosecongênitaresultanumimpactosocioeconômicoimportante, principalmente se a criança for afetada por retardo mental e cegueira. Nos EUA, estima-se que a cada ano nasçam cerca de 3.000 crianças com toxoplasmose congênita e o custo anual associado aos cuidados com estas crianças é de US\$ 31 a 40 milhões. (SPARKES, 1998). 